\title{
Minder lichamelijke belasting door opgehoogd metselen
}

\author{
P.A.J. Luijsterburg • P.M. Bongers • E.M.M. de Vroome
}

Samenvatting In dit artikel worden de resultaten beschreven van een gecontroleerd interventieonderzoek naar het effect van de invoering van metselmethoden waarbij op hoogte wordt gewerkt, op de lichamelijke belasting, op klachten aan het bewegingsapparaat, op het ziekteverzuim en op de arbeidstevredenheid van metselaars. Uit deze resultaten blijkt dat het invoeren van hulpmiddelen om opgehoogd te kunnen metselen, leidt tot tevreden gebruikers en verminderde belasting van de rug en, hoewel in mindere mate, ook van de schouders en armen. Door inzet van de hulpmiddelen wordt niet $60 \%$ maar $40 \%$ van de werktijd met een gebogen romp gewerkt. Het invoeren van de hulpmiddelen heeft weinig effect op het aantal keer tillen, wel wordt het biomechanisch moment verlaagd. Er is geen reductie van klachten door inzet van de hulpmiddelen aangetoond. Wel lijkt het ziekteverzuim te zijn gedaald. De resultaten laten tevens zien dat het merendeel van de metselaars een groot voorstander van gebruik van de hulpmiddelen is. Op grond van deze resultaten wordt aanbevolen het op hoogte metselen verder in te voeren in de bouw.

P.A.J. Luijsterburg $(\bowtie)$

PersonaliaP.A.J. (Pim) Luijsterburg is wetenschappelijk onderzoeker bij het Erasmus MC, afdeling

Huisartsgeneeskunde, Rotterdam.P.M. (Paulien) Bongers is hoogleraar preventieklachten bewegingsapparaat bij intensivering van arbeid bij TNO Arbeid, Hoofddorp en Body@work, Onderzoekscentrum bewegen, arbeid en gezondheid TNO-VU, Amsterdam.E.M.M. (Ernest) de Vroome is statisticus bij TNO Arbeid, Hoofddorp. CorrespondentieadresPim Luijsterburg, Erasmus MC, Afdeling huisartsgeneeskunde, Postbus 1738, 3000 DR

Rotterdam.E-mail: p.luijsterburg@erasmusmc.nl
Keywords arbeidsomstandigheden · opgehoogd metselen $\cdot$ rugklachten $\cdot$ interventie $\cdot$ lichamelijke belasting $\cdot$ ziekteverzuim

\section{Inleiding}

In Nederland werken ongeveer 20.000 metselaars en 7.000 oppermannen in de bouw (20\% van de bouwpopulatie). Over het algemeen bestaat een metselploeg uit drie metselaars en één opperman die meestal een vast team vormen. Het werk van een metselaar bestaat voornamelijk uit het oppakken van bakstenen en het plaatsen van deze stenen in een muur. Een metselaar verwerkt gemiddeld 800 à 1000 stenen per dag. De stenen worden achter de metselaar op de grond neergelegd en om die reden buigt en draait een metselaar zijn rug ten minste 800 à 1000 keer per dag. ${ }^{1}$ Het metselen gaat dus gepaard met een hoge fysieke belasting. Het werk van een opperman bestaat hoofdzakelijk uit het laden van metselstenen op een stenenwagen, het transporteren van deze stenen naar de metselaar, en het weer afladen van de stenen. Daarnaast voorziet de opperman de metselaars van de benodigde specie. Eén opperman transporteert ongeveer 2400 tot 3000 stenen per dag. ${ }^{1}$

In de literatuur bestaat consensus over het feit dat langdurig achtereen frequent bukken en draaien van de romp een verhoogd risico op rugklachten geeft. ${ }^{2-8}$ Veelvuldig buigen van de nek en werken met geheven armen kunnen leiden tot nek- en schouderklachten. ${ }^{8-13}$ Recent is in de literatuur ${ }^{8}$ het effect van interventies gericht op verbetering van rug-, nek-, schouder- en armbelasting uitgebreid geïnventariseerd in opdracht van de National Research Council in Amerika. Uit dit rapport blijkt dat er slechts één gecontroleerde ergonomische interventie is 
figuur 1a Opgehoogd metselen met behulp van metseltafels.

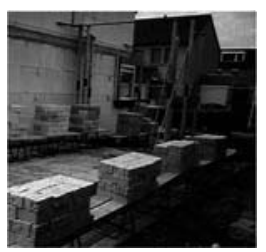

uitgevoerd die niet in een kantooromgeving plaatsvindt waarbij ook naar een gezondheidsuitkomst is gekeken. Hoge tevredenheid over het gebruik van hulpmiddelen om opgehoogd te metselen werd gevonden in een recent onderzoek onder 567 metselaars in Nederland. ${ }^{14}$ Uit deze inventarisatie van Arbouw blijkt, dat anno 2001 $37 \%$ van de metselaars 'af en toe' of vaker de stenen tijdens het metselen op een verhoging heeft staan.

In een ander onderzoek ${ }^{15}$ werd een reductie van $20 \%$ in ziekteverzuim en $70 \%$ in personeelsverloop gerealiseerd door invoering van een uitgebreide ergonomische en organisatorische interventie bij een fabriek waar motorkettingzagen werden geproduceerd (in vergelijking tot een controle bedrijf).

In de afgelopen jaren hebben de Aannemers Vereniging Metselwerken (AVM), het Koninklijk verbond van Nederlandse Baksteenfabrikanten (KNB) en de Nederlandse Vereniging van Onderaannemers in de Bouwnijverheid (NVOB) in samenwerking met TNO Bouw een werkmethode ontwikkeld die bestaat uit opgehoogd metselen en mechanisch opperen. Bij het opgehoogd metselen worden de stenen en specie op $50 \mathrm{~cm}$ hoogte bij de metselaar geplaatst. Dit gebeurt o.a. door het gebruik van metseltafels, consoles aan de steiger en hefsteigers (zie figuur 1a en 1b).

Bij het mechanisch opperen worden de stenen door middel van een kraan, verreiker ${ }^{1}$ of een opkar bij de metselaar gebracht. Ook is er een mogelijkheid om de specie met behulp van een verreiker, kraan of een pompsysteem te verplaatsen.

In opdracht van de Commissie Sociaal Economische Gezondheidsverschillen (SEGV) II van Zorg Onderzoek Nederland heeft TNO Arbeid een onderzoek verricht naar de effectiviteit van deze nieuwe werkmethoden (opgehoogd metselen). In de weergegeven resultaten staan de volgende vraagstellingen centraal:

1. Resulteert het invoeren van opgehoogd metselen in een vermindering van de fysieke werkbelasting van rug, schouder, arm en pols bij de metselaar?

2. Resulteert het invoeren van opgehoogd metselen in een vermindering van de klachten en aandoeningen aan het bewegingsapparaat bij de metselaar?

\footnotetext{
${ }^{1}$ Een verreiker is een multifunctioneel voertuig op vier wielen waarmee met behulp van diverse hulpstukken stenen, specie en steigermateriaal kan worden geopperd.
}

figuur 1b Opgehoogd metselen met behulp van consoles aan de steiger.

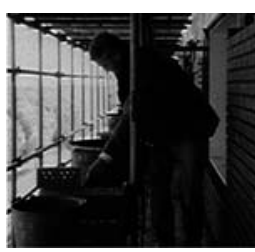

3. Resulteert het invoeren van opgehoogd metselen in een vermindering van het arbeidsverzuim bij de metselaar?

4. Resulteert het invoeren van opgehoogd metselen in een verhoogde arbeidstevredenheid bij de metselaar?

Tevens is gevraagd naar de ervaringen en tevredenheid van de metselaars met het gebruik van de hulpmiddelen die worden gebruikt voor het opgehoogd metselen.

1. Opgehoogd metselen leidt tot verminderde belasting van rug, schouders en armen.

2. Opgehoogd metselen leidt niet tot reductie van klachten aan het bewegingsapparaat.

3. Door opgehoogd metselen lijkt het ziekteverzuim te dalen.

4. Metselaars zijn een groot voorstander van het opgehoogd metselen.

\section{Methode}

\section{Onderzoeksopzet}

Gezien het feit dat de nieuwe werkmethode per metselbedrijf werd ingevoerd, was het niet mogelijk de individuele deelnemers aan het onderzoek te randomiseren over een interventie- en vergelijkingsgroep. Gezien de vereiste investeringen was het ook niet mogelijk de bedrijven te randomiseren over een interventie- en vergelijkingsgroep. Voor een effectieve randomisatie zouden bovendien veel verschillende bedrijven mee moeten doen. Gezien deze beperkingen is gekozen voor een gecontroleerd interventieonderzoek met een voor- en nameting. Bij de bedrijven die overgingen op het opgehoogd metselen hebben voormetingen plaatsgevonden van juli 1997 tot en met maart 1998, op het moment van toetreding tot de studie. De nametingen hebben plaatsgevonden van juni 1998 tot en met april 1999, telkens ongeveer 10 maanden na de voormetingen. In diezelfde perioden hebben ook metingen plaatsgevonden bij de bedrijven die niet op het opgehoogd metselen overschakelden.

\section{Lichamelijke belasting}

De duur van de verschillende taken van de metselaars is gedurende de hele werkdag direct geobserveerd. 
Vervolgens is van de belangrijkste taken de houdingsbelasting en krachtuitoefening bepaald vanaf videoopnames. De gemiddelde dagdosis is vervolgens geschat als een tijdgewogen gemiddelde van de belasting tijdens de verschillende taken. De effectmaten voor het bepalen van de fysieke werkbelasting van rug en arm zijn de duur en frequentie van rugflexie en armelevatie. De houdingsbelasting is bepaald via observatie vanaf videobeelden. Vanaf de beelden zijn de duur en frequentie van rugflexie $\left(>30^{\circ}\right.$ en $\left.>60^{\circ}\right)$ en armelevatie $\left(>30^{\circ}\right.$ en $\left.>60^{\circ}\right)$ geobserveerd.

\section{Klachten bewegingsapparaat}

De periode prevalentie (10 maanden) rug-, schouder- en polsklachten is bepaald met een aangepaste versie van Nederlandse vertaling van de Nordic Questionnaire. ${ }^{16,}$ 17

\section{Ziekteverzuim}

Met de vragenlijst is ook het ziekteverzuim tijdens het onderzoek nagevraagd. Aan de metselaars is gevraagd of ze zich in de afgelopen tien maanden wel eens ziek hebben gemeld op het werk, en wat de frequentie (het aantal keer) en de totale lengte van het verzuim (in kalenderdagen) waren. Naast zelf gerapporteerd verzuim is alle deelnemende bedrijven ook gevraagd een opgave te doen van het geregistreerde verzuim. Deze laatste gegevens zijn echter door weinig bedrijven verstrekt en hierdoor niet bruikbaar als uitkomstmaat.

\section{Arbeidstevredenheid}

Arbeidstevredenheid is nagevraagd met enkele vragen uit de Work Apgar lijst. ${ }^{18}$ Met een vragenlijst is de ervaring van de werknemers met het werken met de verschillende hulpmiddelen nagevraagd.

Voor elke metselploeg uit de interventiegroep is gedurende de looptijd van de interventie (10 maanden) op een registratieformulier, de werklijst, bijgehouden welk gedeelte van de werktijd de nieuwe metselmethode werd toegepast.

\section{Analyse van de onderzoeksgegevens}

Voor het beantwoorden van de vraagstellingen worden de veranderingen in de effectmaten tussen voor- en nameting in de interventiegroep vergeleken met dezelfde gegevens uit de vergelijkingsgroep. Met behulp van Ttoetsen is bekeken of deze veranderingen statistisch significant van elkaar afwijken.

\section{Resultaten}

Onderzoekspopulatie

Vijfentwintig bedrijven (60 ploegen: 202 metselaars en 56 oppermannen) hebben deelgenomen aan het onderzoek. Van deze metselaars zouden volgens eigen opgaaf 130 metselaars traditioneel blijven werken (vergelijkingsgroep) en zouden 72 metselaars het opgehoogd metselen invoeren (interventiegroep). Lopende het onderzoek bleek echter uit de werklijsten dat de nieuwe metselmethode niet in alle ploegen uit de interventiegroep goed was doorgevoerd. De bedrijven gaven hiervoor diverse redenen aan: (1) de hoge kosten van de nieuwe werkmethode die niet konden worden doorberekend in het tarief; (2) in de onderaanneming zijn ingehuurde metselbedrijven afhankelijk van het door de hoofdaannemer geleverde materiaal; en (3) er vindt geen goed overleg plaats tussen de metselbedrijven en aannemer over hoe er gewerkt gaat worden.

Van de 72 metselaars waarvan verwacht werd dat ze zouden overschakelen op het opgehoogd metselen bleken 28 metselaars minder dan $50 \%$ van de werktijd opgehoogd gemetseld te hebben gedurende de interventieperiode. Deze metselaars zijn toegevoegd aan de vergelijkingsgroep. Hierdoor bestaat de uiteindelijke vergelijkingsgroep uit 158 metselaars. De resterende 44 metselaars, die meer dan $50 \%$ van de follow-up tijd opgehoogd metselde vormen de interventiegroep.

De metselaars zijn gemiddeld 38 jaar oud, hebben vrijwel allemaal de lagere school afgemaakt en daarna een beroepsopleiding gevolgd. De meerderheid van de interventiegroep is werkzaam in de Randstad terwijl dit bij de vergelijkingsgroep een minderheid betreft.

Loss to follow-up

De vragenlijst tijdens de voormeting en de nameting is ingevuld door respectievelijk $78 \%$ en $52 \%$ van de metselaars (tabel 1).

Van $48 \%$ van de metselaars zijn vragenlijstgegevens van de voor-én nameting beschikbaar.

In het onderzoek heeft bij $25 \%$ van de metselaars $(n=$ 11 , één metselaar van alle ploegen) uit de interventiegroep en bij $13 \%$ van de metselaars $(n=20$, één metselaar van de helft van de ploegen) uit de vergelijkingsgroep een voormeting en een nameting op de bouwplaats plaatsgevonden. De gemeten waarden zijn geëxtrapoleerd naar de andere metselaars binnen de eigen metselploeg. Totaal waren er gegevens beschikbaar van 41 metselaars uit de interventiegroep en van 67 metselaars uit de vergelijkingsgroep over de lichamelijke belasting. In de vergelijkingsgroep zijn de metselaars uit de 
Tabel 1 Gegevens voor de verschillende uitkomstmaten voor metselaars. $N=$ het aantal deelnemers per (sub)groep.

\begin{tabular}{|c|c|c|}
\hline & \multicolumn{2}{|c|}{ Metselaars } \\
\hline & $\begin{array}{r}\text { Interv. } N \\
(\%)\end{array}$ & $\begin{array}{r}\text { Verg. } N \\
(\%)\end{array}$ \\
\hline Deelnemers voormeting & 44 & 158 \\
\hline Deelnemers voor- én nameting ${ }^{1}$ & $43(98)$ & $131(83)$ \\
\hline Voor- én nameting buigen rug ${ }^{1}$ & $38(86)$ & $67(42)$ \\
\hline Voor- én nameting buigen pols ${ }^{1}$ & $41(93)$ & $75(47)$ \\
\hline $\begin{array}{l}\text { Voor- én nameting } \\
\text { krachtuitoefening } 1\end{array}$ & $41(93)$ & $76(48)$ \\
\hline Voormeting vragenlijst $^{1}$ & $39(89)$ & $119(75)$ \\
\hline Nameting vragenlijst ${ }^{2}$ & $31(70)$ & $74(50)$ \\
\hline Voor- én nameting vragenlijst ${ }^{1}$ & $30(68)$ & $67(42)$ \\
\hline Voor- én nameting rugklachten ${ }^{1}$ & $28(64)$ & $61(39)$ \\
\hline $\begin{array}{l}\text { Voor- én nameting } \\
\text { schouderklachten }^{1}\end{array}$ & $24(55)$ & $64(41)$ \\
\hline
\end{tabular}

metselploegen waar niemand is gemeten voor de lichamelijke belastingsmaten buiten beschouwing gelaten. De aantallen voor de verschillende uitkomstmaten verschillen door verschillen in ontbrekende waarden (tabel 1).

\section{Gebruik van hulpmiddelen}

Het merendeel van de metselaars is een groot voorstander van het gebruik van de hulpmiddelen (60 tot $80 \%$ afhankelijk van het soort hulpmiddel). Tevens is het merendeel van de gebruikers van mening dat de kwaliteit van het werk gelijk blijft, dan wel toeneemt afhankelijk van het hulpmiddel. Als voordelen voor het gebruik van de innovatieve metselsystemen worden genoemd dat er lichter en sneller gewerkt kan worden en dat het minder belastend is voor de rug. Er worden slechts een beperkt aantal nadelen genoemd zoals het sjouwen met meer materiaal (de hulpmiddelen zelf) en de steigers die voller zijn.

\section{Lichamelijke belasting}

Uit tabel 2 blijkt in de interventie groep niet $60 \%$ maar slechts $40 \%$ van de werktijd met een gebogen romp van meer dan $30^{\circ}$ wordt gewerkt. Dit is een afname van $20 \%$ terwijl in de vergelijkingsgroep een afname van ca. $10 \%$ is gemeten.

Het blijkt dat in de vergelijkingsgroep 3,5 uur en in de interventiegroep 3 uur gewerkt wordt in een gebogen houding op een werkdag. In de interventiegroep daalt het percentage van de werktijd dat met een sterk gebogen romp (meer dan $60^{\circ}$ ) wordt gewerkt van ongeveer $40 \%$ naar ongeveer $20 \%$. In de vergelijkingsgroep was de afname ca. 5\%. Bij inzet van de hulpmiddelen wordt hierdoor niet ruim 2 uur, maar ongeveer 1 uur en 20 minuten met een sterk gebogen romp gewerkt, terwijl in de vergelijkingsgroep de duur dat in een dergelijke houding werd gewerkt iets toenam.

Metselaars werken veel met de armen geheven boven de $30^{\circ}$. Na de interventie daalt het percentage van de werktijd dat in een dergelijke houding wordt gewerkt van $67 \%$ naar ongeveer $60 \%$. Omdat in de vergelijkingsgroep een lichte toename werd vastgesteld, kan worden geconcludeerd dat in de interventiegroep ten opzichte van de vergelijkingsgroep een reductie in werken met geheven armen van ca. $10 \%$ van de werktijd wordt gerealiseerd. In de interventiegroep wordt na het invoeren van hulpmiddelen ook niet $30 \%$ maar ca. $20 \%$ van de werktijd met sterk geheven armen $\left(>60^{\circ}\right)$ gewerkt. $\mathrm{Na}$ overschakelen op gebruik van hulpmiddelen wordt dus ca. 30 minuten korter met matig geheven armen $\left(30^{\circ}\right)$ en 20 minuten korter met sterk geheven armen $\left(60^{\circ}\right)$ gewerkt op een werkdag.

Inzet van de hulpmiddelen heeft weinig effect op het aantal keer tillen van de metselaars. Doordat echter door inzet van de hulpmiddelen de verticale afstand waarover moet worden getild afneemt, hetgeen blijkt uit de afname van de buiging van de rug, zal ook het biomechanisch moment afnemen.

\section{Klachten bewegingsapparaat}

Tabel 3 laat zien dat de incidenties van klachten aan het bewegingsapparaat, voor en na de invoering van opgehoogd metselen niet verschillen. Dit geldt voor zowel rugklachten, schouderklachten als voor klachten aan de hand/pols en voor alle verschillende operationalisaties van de klachten en voor werkgebonden klachten.

\section{Ziekteverzuim}

Uit tabel 4 blijkt dat het aantal metselaars dat aangeeft dat zij de afgelopen 10 maanden hebben verzuimd door ziekte in de interventiegroep met $20 \%$ is gedaald terwijl het in de vergelijkingsgroep met $8 \%$ is gestegen.

Ook is de zelfgerapporteerde frequentie van het verzuim bij de metselaars uit de interventiegroep gedaald terwijl het in de vergelijkingsgroep is gestegen. De effecten van de zelfgerapporteerde verzuimduur, van het 'werkgebonden' verzuim en van het specifieke verzuim door rug- en schouderklachten zijn eveneens in dezelfde richting maar minder uitgesproken. 
Tabel 2 Gemiddelde scores tijdens voor- en nameting en verandering tussen voor- en nameting in de interventie- en vergelijkingsgroep.

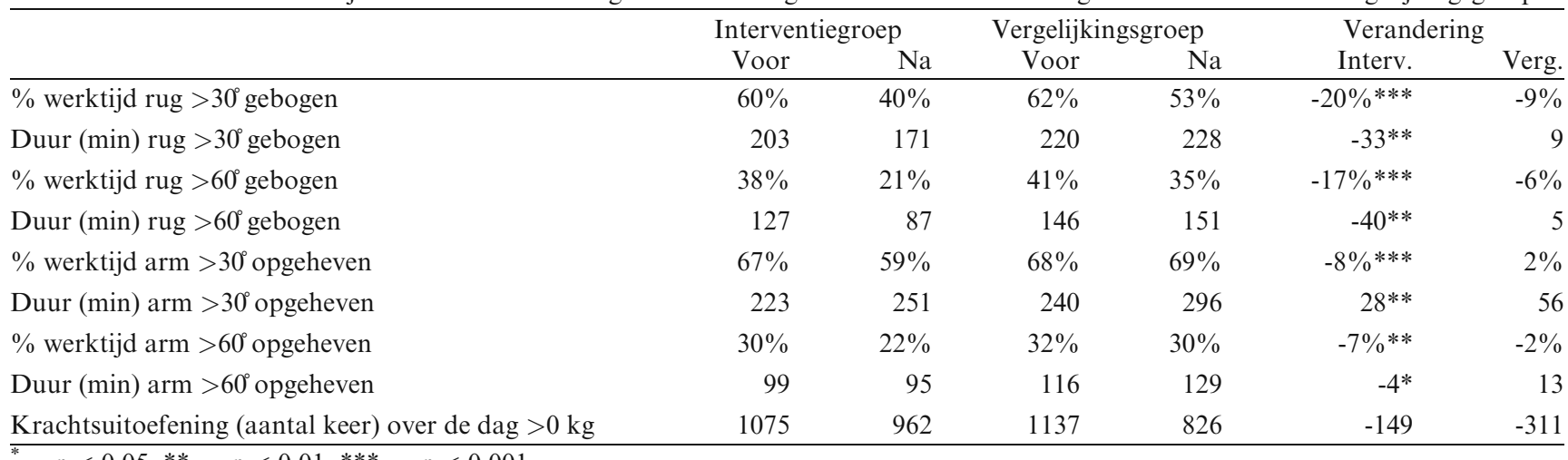

$\stackrel{*}{*}=p<0,05, * *=p<0,01, * * *=p<0,001$

Tabel 3 Gemiddelde percentage klachten tijdens voor- en nameting en verandering tussen voor- en nameting in de interventie- en vergelijkingsgroep.

\begin{tabular}{|c|c|c|c|c|c|c|}
\hline & \multicolumn{2}{|c|}{ Interventiegroep } & \multicolumn{2}{|c|}{ Vergelijkingsgroep } & \multicolumn{2}{|c|}{ Verandering } \\
\hline & Voor & $\mathrm{Na}$ & Voor & $\mathrm{Na}$ & Interv. & Verg. \\
\hline Regelmatige of langdurige lage-rugklachten & 54 & 54 & 51 & 56 & 0 & 5 \\
\hline Lage-rugklachten door werk & 50 & 50 & 44 & 49 & 0 & 5 \\
\hline Regelmatige of langdurige schouderklachten & 11 & 22 & 16 & 19 & 11 & 3 \\
\hline Schouderklachten door werk & 11 & 11 & 10 & 13 & 0 & 3 \\
\hline Regelmatige of langdurige polsklachten & 27 & 31 & 25 & 27 & 4 & 2 \\
\hline Polsklachten door werk & 27 & 23 & 17 & 23 & -4 & 6 \\
\hline
\end{tabular}

Tabel 4 Zelfgerapporteerd verzuim tijdens voor- en nameting en verandering tussen voor- en nameting in de interventie- en vergelijkingsgroep.

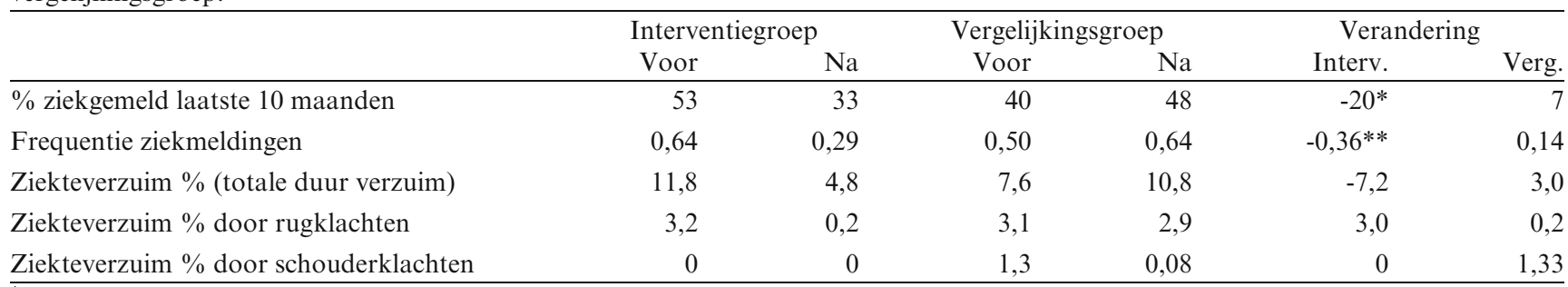

${ }^{*}=p<0,05, * *=p<0,01$

Arbeidstevredenheid

Uit tabel 5 blijkt dat de metselaars vaak plezier in het werk hebben. Dit verandert niet tussen de voor- en nameting, noch in de interventiegroep, noch in de vergelijkingsgroep.

\section{Discussie}

\section{Zelfselectie}

In dit onderzoek heeft de interventie plaatsgevonden bij bedrijven die zelf hadden besloten hulpmiddelen in te voeren. Hierdoor kunnen de interventiebedrijven een selectie uit de metselbedrijven zijn waardoor mogelijk de twee groepen bedrijven niet goed met elkaar te vergelijken zijn. De metselaars uit de interventie- en vergelijkingsgroep blijken echter redelijk met elkaar overeen te komen behalve dat het bruto maandloon van de metselaars in de interventiegroep hoger ligt dan dat van de vergelijkingsgroep, en de metselaars uit de interventiegroep vaker werkzaam zijn in de Randstad dan die uit de vergelijkingsgroep. De bedrijven uit de interventiegroep die wel van plan waren hulpmiddelen in te voeren maar dat niet of onvoldoende hebben gedaan, en waarvan de metselaars zijn toegevoegd aan de controlegroep, waren waarschijnlijk goed vergelijkbaar met de interventiegroep, voor wat betreft de geneigdheid tot innoveren. De bedrijven waren immers van plan de hulpmiddelen te gaan gebruiken. 
Tabel 5 Arbeidstevredenheid tijdens voor- en nameting en verandering tussen voor- en nameting in de interventie- en vergelijkingsgroep.

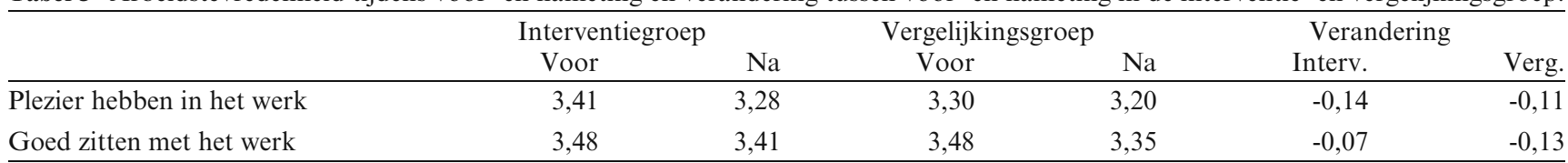

Plezier in het werk: (1) vrijwel nooit tot en met (4) (bijna) altijd.

Goed zitten met het werk: (1) niet goed tot en met (4) goed.

Indeling interventie- en vergelijkingsgroep

Door metselaars die niet of onvoldoende opgehoogd hebben gemetseld van de interventiegroep naar de vergelijkingsgroep te verplaatsen, is het contrast tussen beide groepen mogelijk verkleind. Hier is voor gekozen om de power van het onderzoek niet verder te verkleinen. In een aanvullende analyse is onderzocht of handhaven van de indeling volgens 'intentie tot opgehoogd metselen' tot dezelfde uitkomsten had geleid. Dat bleek inderdaad het geval.

\section{Loss to follow-up en effectmaten}

De respons op de vragenlijsten was laag (48\%). De nonrespons was minder in de interventiegroep van de metselaars $(32 \%)$ en veel groter in de referentiegroep bij de metselaars $(58 \%)$.

De lage respons bij de vergelijkingsgroep is grotendeels veroorzaakt door verandering van bedrijf van die metselaars. Bij één controle bedrijf ging het bijvoorbeeld om drie hele ploegen. In geval van selectieve uitval ten aanzien van de uitkomstmaten die verschillend is in interventie- en vergelijkingsgroep kan dit de resultaten vertekenen. Er zijn geen gegevens op grond waarvan een oordeel gevormd kan worden over de selectiviteit van de respons. Omdat het niet is gelukt voldoende gegevens van het geregistreerde verzuim bij de bedrijven te achterhalen is in dit artikel het effect op zelfgerapporteerd verzuim gepresenteerd. Indien de respons op de vragenlijst selectief is ten aanzien van verzuim én dit verschilt in interventiegroep en vergelijkingsgroep kunnen de resultaten zijn vertekend. Dit geldt waarschijnlijk niet voor de ontbrekende vragenlijsten vanwege verandering van baan maar mogelijk wel voor een ander deel van respondenten, bijvoorbeeld door afwezigheid door ziekte.

\section{Duur follow-up}

Het is mogelijk dat de follow-up duur van 10 maanden te kort was om een effect van de verminderde belasting op vermindering van klachten te bewerkstelligen. Dat wel een effect op verzuim is gevonden, kan verklaard worden doordat de klachten weliswaar niet in aantal of duur zijn afgenomen, maar wel in ernst waardoor met de klachten doorgewerkt kan worden. Tevens is het denkbaar dat door de verminderde lichamelijke belasting dezelfde klachten tot minder verzuim aanleiding geven, omdat men langer door kan werken met klachten en men sneller het werk weer kan hervatten.

\section{Beschouwing}

Effect van gebruik hulpmiddelen door oppermannen op de lichamelijk belasting

Op grond van de beperkte aantallen oppermannen kunnen geen uitspraken worden gedaan over het effect van invoeren van de hulpmiddelen voor mechanisch opperen op de lichamelijk belasting van de oppermannen. De beschikbare gegevens wijzen niet op een duidelijke verbetering van de lichamelijke belasting; ook geen verslechtering.

\section{Voorbeeld werking van de interventie}

De Stichting Arbouw, waarin werkgevers en werknemers in de bouw zijn vertegenwoordigd heeft een aantal concrete doelstellingen geformuleerd en is een zogenoemd 'goalsetting' programma gestart: in vier jaar tijd moeten metselaars, stratenmakers en timmerlieden $10 \%$ minder tilbelasting ondervinden in hun werk, moeten ze $10 \%$ meer hulpmiddelen gebruiken en moet dat resulteren in $10 \%$ minder gezondheidsklachten die het gevolg (kunnen) zijn van tillen. ${ }^{17}$ De resultaten van het voorliggende onderzoek, kunnen in dit programma gebruikt worden om een effectieve implementatie van hulpmiddelen te bewerkstelligen voor metselaars, maar kunnen ook als voorbeeld dienen voor andere beroepen in de bouw.

\section{Relevantie voor arbeids- en bedrijfsgeneeskundigen}

Op grond van de resultaten verdient het aanbeveling om metselaars in de bouw en hun werkgevers te stimuleren om opgehoogd metselen in te voeren met het oog op tevredenheid op het werk en minder lichamelijke belasting en met kans op vermindering van verzuim. 


\section{Literatuur}

Vink P, Miedema M, Koningsveld E, Molen H van der. Physical effects of new devices for bricklayers. Int J Occup Saf Ergon 2002; 8(1): 71-82.

Riihimaki H. Low-back pain, its origin and risk indicators. Scand J Work Environ Health 1991; 17(2): 81-90.

Burdorf A, Sorock G. Positive and negative evidence of risk factors for back disorders. Scand J Work Environ Health 1997; 23(4): 243-256.

Hoogendoorn WE, Bongers PM, Vet HC de, et al. High physical work load and low job satisfaction increase the risk of sickness absence due to low back pain: results of a prospective cohort study. Occup Environ Med 2002; 59(5): 323-328.

Hoogendoorn WE, Bongers PM, Vet HC de, et al. Psychosocial work characteristics and psychological strain in relation to low-back pain. Scand J Work Environ Health 2001; 27(4): 258-267.

Hoogendoorn WE, Bongers PM, Vet HC de, et al. Flexion and rotation of the trunk and lifting at work are risk factors for low back pain: results of a prospective cohort study. Spine 2000; 25 (23): 3087-3092.

Hoogendoorn WE, Poppel MN van, Bongers PM, et al. Physical load during work and leisure time as risk factors for back pain. Scand J Work Environ Health 1999; 25(5): 387-403.

Medicine. Commission on Behavioral and Social Sciences and Education. Washington, DC: National Academy Press, 2001.

Ariens GA, Mechelen W van, Bongers PM, et al. Physical risk factors for neck pain. Scand J Work Environ Health 2000; 26(1): 7-19.
Ariens GA, Bongers PM, Hoogendoorn WE, et al. High quantitative job demands and low coworker support as risk factors for neck pain: results of a prospective cohort study. Spine 2001; 26 (17): 1896-1901; discussion 1902-1903.

Ariens GA, Bongers PM, Douwes M, et al. Are neck flexion, neck rotation, and sitting at work risk factors for neck pain? Results of a prospective cohort study. Occup Environ Med 2001; 58 (3): 200-207.

Ariens GA, Bongers PM, Hoogendoorn WE, et al. Physical and psychosocial load at work and sickness absence due to neck pain. Scand J Work Environ Health 2002; 28(4): 222-231.

Health Council of the Netherlands. RSI. The Hague: Health Council of the Netherlands, 2000; publication No. 2000/22.

Koningsveld EAP, Eikhout SM, Molen HF van der, et al. Vermindering van tilbelasting met $10 \%$ bij metselaars, stratenmakers en timmerlieden: rapportage van de vier fasen. Hoofddorp: TNO Arbeid, 2001.

Parenmark GA, Malmqvist AK, Ostengren R. Ergonomics in an engineering industry; effect on sick leave frequency, labour turnover and productivity. Int $\mathbf{J}$ Ind Ergonomics 1993; 11: 291-300.

Kuorinka I, Jonsson B, Kilbom A, et al. Standardised Nordic questionnaire for the analysis of musculoskeletal symptoms. Appl Ergonomics 1987; 18: 233-237.

Hildebrandt VH, Bongers PM, Dijk FJ van, et al. Musculoskeletal Questionnaire: description and basic qualities. Ergonomics 2001; 44(12): 1038-1055.

Bigos SJ, Battie MC, Spengler DM, et al. A longitudinal, prospective study of industrial back injury reporting. Clin Orthop 1992; (279): 21-34 